\title{
Sensitivity of Pyrenophora Teres Pathotypes to Temperature Variation and Effects on Virulence and Pathogenicity
}

\author{
Javan Omondi Were ${ }^{1 *}$, Julius Onyango Ochuodho ${ }^{1}$, Nicholas Kipkemboi Rop ${ }^{1}$, \\ Elizabeth Nabwile Omami ${ }^{1}$, Victoria Esther Anjichi ${ }^{1}$, Presley Mostyn Ouma Odero ${ }^{1}$, \\ Lydia Chepkoech Kimno ${ }^{2}$, Abigael Adhiambo Owino ${ }^{3}$ \\ ${ }^{1 *}$ University of Eldoret, School of Agriculture and Biotechnology, Department of Seed, Crop and \\ Horticultural Sciences, Eldoret, Kenya. \\ ${ }^{2}$ Ministry of Agriculture, Livestock and Fisheries, Department of Agriculture - \\ Crops Section, Iten, Kenya. \\ ${ }^{3}$ Kenya Agriculture and Livestock Research Organization, Tea Research Institute, \\ Department of Integrated Pest and Disease Management, Kericho, Kenya
}

\begin{abstract}
Mixed information on the appropriate temperature required by $P$. teres $f$. teres pathotypes for successful infection of barley is one of the bottlenecks especially on sensitive studies on virulence and pathogenicity that require specific conditions. The study aimed at determining how morphologically diverse species of P. teres respond to different temperature regimes at different time interval. Infected leaf tissues were collected from major barley growing zones representing high, medium and low altitudes. Isolation was done from these tissues in pathology laboratory and three morphologically distinct pathotypes from high and low altitudes selected for virulence and pathogenicity assessment. Susceptible barley variety (Sabini) was then planted in split-split plot experimental arrangement in randomized complete block design with three replicates. Severity data was scored on a 1-5 scale, transformed as $\log _{10}(x+1)$ then subjected to analysis of variance on Genstat statistical software release 14.1 at 5\% level of significance. A significant difference between the means for isolates and temperature ranges was separated using contrast, comparison. Isolates, temperature regimes and all the interactions had significant effect on severity $(p<0.05)$. This indicates that each of the factors had additive effect on the disease level. However, time interval alone was not significant ( $p>0.05)$. The 'Chep 3' isolate from medium altitude was most virulent at $30-40^{\circ} \mathrm{C}$ while the 'Mau 6' from high altitude was the most sensitive to temperature and time variation, indicating that these pathotypes are could be adapted to specific zones. Therefore, temperature plays vital role in virulence and pathogenicity but this also depends on time of exposure and strain of the pathogen.
\end{abstract}

Keywords: Sensitivity, Pyrenophora teres, temperature variation, virulence, pathogenicity

\section{INTRODUCTION}

Net blotch is one of the major fungal disease affecting barley production in Kenya and other parts of the world (Bekele et al., 2001; Owino et al., 2013; Owino et al., 2014). There are two forms of net blotch, the net form and the spot form. Net form of net blotch (NFNB), caused by the fungus Pyrenophora teres f. teres, is the most common form and occurs wherever barley is grown. Spot form of net blotch (SFNB) is caused by the fungus Pyrenophora teres f. maculata (McLean et al., 2009). The net-type net blotch is the most common in Kenya (Owino et al., 2014) especially in Moiben, Mau Narok, Mount Kenya and Nakuru regions which represent low, medium and high altitude zones (EABL-UoE, 2013). Under favorable environmental conditions for infection, this disease can cause yield losses ranging between 15 - 40\% (EABL-UoE, 2010) thus a huge financial loss to the farmers when not controlled properly.

A number of studies have been conducted with an attempt to address the challenges caused by this disease especially with focus on morphological and genetic diversity (Bentata et al., 2011; Owino et al., 2013), response of different barley varieties to the disease as well as the temperature ranges needed by the pathogen for optimal infection (McLean et al., 2009). However, the disease still remains a major challenge especially on temperature ranges required by the pathogen for successful infection to occur, the effect of different temperature ranges on virulence and pathogenicity and how different strains of these pathogenic fungi respond to the extreme temperatures which is usually 
observed under the field conditions where the crop is grown. Additionally, a number of authors have reported different and conflicting temperature ranges for optimum infection by the fungus. For instance, the highest infection by P. teres $\mathrm{f}$. teres has been observed under 10 hours of photoperiod at $25{ }^{\circ} \mathrm{C}$ (Kosiada, 2008). In Kenya, areas with as low as $6-14{ }^{\circ} \mathrm{C}$ and as high as $22-26{ }^{\circ} \mathrm{C}$ (Mau Narok) temperature ranges and a minimum of 12 hours photoperiod in high altitude zones have recorded high disease levels (Owino et al., 2014).

Most pathogen evolves into new strains not only due to the resistance mechanisms by the host plant but also due to extreme environmental conditions (Agrios, 2005). In terms of P. teres, a total of five morphologically diverse pathotypes have been isolated from infected tissues obtained from major barley growing zones in Kenya (Owino et al., 2013), an indication of existence of new strains of the pathogen. This could be some of the reasons for higher disease levels even with increased effect of global warming and extremely higher daily temperatures as high as $35{ }^{\circ} \mathrm{C}$ in the tropics thus making the disease to remain a major challenge in Kenya with similar environmental conditions.

With the increased temperatures in the tropics and sub-tropics coupled with the availability of newly evolved pathogenic trains of $P$. teres and increased severity of the disease on barley (Owino et al., 2013), the temperature ranges in literature remains lower than the true representation of the environment. This therefore necessitates the need to establish the most current information on the sensitivity of these fungi to a wider temperature range and how virulence and pathogenicity relates to such different temperature ranges. The information is very vital to plant protectionist aiming at managing this disease under different temperature conditions in the world.

\section{MAterials AND MeTHODS}

Net blotch infected barley leaf tissues were sourced from Mau Narok and University of Eldoret, Chepkoilel barley trial sites. Isolation and purification was done as outlined by Owino et al., (2013) where the infected leaf samples were cut into $1 \mathrm{~cm}^{2}$ pieces and surface-sterilized with $1 \%$ sodium hypochlorite solution for $30 \mathrm{sec}$, then rinsed three times in sterile distilled water for $10 \mathrm{sec}$. Leaf pieces were blotted to remove excess water and aseptically transferred to freshly prepared full strength potato dextrose agar (PDA Oxoid, $3.9 \%$ ) in petri dishes and incubated at $15-20{ }^{\circ} \mathrm{C}$ for $12 \mathrm{hr} / 12 \mathrm{hr}$ light/dark period inside a Gallenkamp incubator to induce sporulation. After five days of incubation, a single conidium was transferred on freshly prepared potato dextrose agar medium and incubated for two weeks under same light and temperature regimes to induce sporulation until three morphologically distinct pure culture of pathogen was obtained (Owino et al., 2013).

One barley variety known to be susceptible to net blotch (Sabini) was planted in $15 \mathrm{~cm}$ diameter plastic containers using triple super phosphate fertilizer that has been thoroughly mixed with two months solarized forest soils to reduce chances of infection by soil inoculum (Were and Ochuodho, 2012b). The experiment was planted in the screenhouse in split-split-plot arrangement in randomized complete block design consisting of three morphologically diverse isolates (whole plots), two time durations (sub-plots) and five thermal temperature regimes (sub-sub-plots). Three replications were used for each set of treatment.

For inoculation, monoconidial isolates of three morphologically diverse isolates of $P$. teres were grown on full-strength PDA plates at $25{ }^{\circ} \mathrm{C}$ under alternating 12 hours white fluorescent light and 12 hours dark cycle for 14 days to induce sporulation (Than et al., 2008). Each plate was then flooded with $5 \mathrm{ml}$ of sterile distilled water, gently swirled and scrapped with a scalpel to harvest macroconidia. The conidial suspensions were passed through a double layer of cheesecloth to retain fragments of mycelia and culture media and transferred into test tubes. The filtered spores of each isolate was adjusted to a concentration of $5 \times 10^{3}$ conidia/ $\mathrm{ml}$ (Xue and Burnett, 1995) after counting on Buker - Turk haemocytometer (Mathur et al., 1989). Barley seedlings were transferred to room temperatures conditions at the plant pathology laboratory for inoculation.

Barley seedlings were inoculated with inoculum of each isolate that has been subjected to $10{ }^{\circ} \mathrm{C}, 30$ ${ }^{\circ} \mathrm{C}, 40{ }^{\circ} \mathrm{C}$ and $50{ }^{\circ} \mathrm{C}$ temperature regimes for one and two minutes separately at Zadoks growth stage 15, usually attained $16-18$ days after seeding (Xue and Burnett, 1995). The seedlings were premoistened with sterile distilled water and inoculated immediately on whole plant with about $0.5 \mathrm{ml}$ of the inoculum per plant. The inoculation chamber was closed immediately to maintain high relative humidity. After inoculation, high relative humidity (> 95\%) was maintained by misting after every 12 hours using sterile distilled water and left at room temperature in normal light regimes (Than et al., 
2008) for about five days to ensure successful infections. From the sixth day, the infected plants were acclimatized for four days and returned to the normal screen house conditions to avoid wilting due to extreme and drastic temperature variation.

Severity of the three $P$. teres pathotypes on barley was assessed on the $14^{\text {th }}$ day after inoculation on a 1 to 5 severity scale (Were and Ochuodho, 2012b) where 1 rating was considered most resistant while 5 as the most susceptible to the disease. The severity data was be subjected to log transformation $\left(\log _{10}(\mathrm{x}+1)\right)$ to ensure normalcy in the distribution curve followed by an analysis of variance on Genstat release 14.1, VSN International Ltd at 5\% level of significance. Contrast comparison was used to separate mean and ascertain whether the temperature regimes and the three isolates had significant effect on virulence and pathogenicity of $P$. teres.

\section{RESULTS AND DISCUSSIONS}

Morphologically diverse isolates and the temperature regimes had significant effect on virulence and pathogenicity of $P$. teres on barley $(p<0.05)$. This implies that different pathotypes responded differently in terms of their ability to infect under different temperature regimes. Increased infection as the temperature rises had been observed by other researchers (Kosaida, 2008). This could also indicate that temperature range used had affected the spore viability thus impacting significantly on pathogenicity of the fungi (Agrios, 2005). In contrast, the timing interval of 1 and 2 minutes did not differ significantly $(p>0.05)$, a possibility of very low differences in the time interval. Additionally, the insignificant effect of time could also mean that the in oculum exposure to various temperature regimes for 1 and 2 minutes did not give much variation in terms of viability thus ability to infect the host plant (Table 1).

\begin{tabular}{l|cllll}
\hline \hline Source of rariation & d.f. & s.s. & m.s. & r.r. & F pr. \\
\hline \hline Rep stratum & 2 & 0.42361 & 0.21181 & 2.980 & \\
Isolate & 2 & 6.46528 & 3.23264 & 45.410 & 0.002 \\
$\quad$ Contrast 1: Chep3 Vs Mau2 & 1 & 6.38021 & 6.38021 & 86.070 & $<.001$ \\
$\quad$ Contrast 2: Chep3 Vs Mau6 & 1 & 1.02083 & 1.02083 & 13.770 & $<.001$ \\
$\quad$ Contrast 3: Mau2 Vs Mau6 & 1 & 2.29688 & 2.29688 & 30.990 & $<.001$ \\
Resid ual & 4 & 0.28472 & 0.07118 & 1.280 & \\
Time & 1 & 0.00347 & 0.00347 & 0.060 & 0.811 \\
Isolatex Time & 2 & 5.00694 & 2.50347 & 45.060 & $<.001$ \\
Resid ual & 6 & 0.33333 & 0.05556 & 0.720 & \\
Temperature & 3 & 6.23264 & 2.07755 & 26.790 & $<.001$ \\
$\quad$ Contrast 1: 10 Vs 30 & 1 & 5.44444 & 5.44444 & 73.450 & $<.001$ \\
$\quad$ Contrast 2: 10 Vs 40 & 1 & 3.06250 & 3.06250 & 41.320 & $<.001$ \\
$\quad$ Contrast 3: 10 Vs 50 & 1 & 3.36111 & 3.36111 & 45.340 & $<.001$ \\
$\quad$ Contrast 4: 30 Vs 40 & 1 & 0.34028 & 0.34028 & 4.590 & 0.037 \\
$\quad$ Contrast 5: 30 Vs 50 & 1 & 0.25000 & 0.25000 & 3.370 & 0.073 \\
$\quad$ Contrast 6: 40 Vs 40 & 1 & 0.00694 & 0.00694 & 0.090 & 0.761 \\
Isolatex Temperature & 6 & 1.42361 & 0.23727 & 3.060 & 0.016 \\
Time x Temperature & 3 & 1.28819 & 0.42940 & 5.540 & 0.003 \\
Isolatex Time x Temperature & 6 & 6.32639 & 1.05440 & 13.600 & $<.001$ \\
Resid ual & 36 & 2.79167 & 0.07755 & & \\
\hline \hline Total & 71 & 30.57986 & & & \\
\hline
\end{tabular}

Table1: Anova abstract for effect of isolate, time, temperature and their interactions on severity of $P$. teres on barley and the contrast comparison for isolate and temperature regimes

In terms of contrast comparison, all pathotypes differed significantly in terms of their virulence and pathogenicity $(p<0.05)$ under different temperature exposure. For instance, isolate labeled 'Chep 3' showed much tolerance to higher temperature regimes and remained infectious even at $50{ }^{\circ} \mathrm{C}$ for two minutes. This pathotype infected the host plant under all temperature regimes but much severity was between $30-40{ }^{\circ} \mathrm{C}$ for two minutes, an indication of ability to withstand higher temperatures by the spores (Agrios, 2005). Contrary to this scenario, isolate labeled 'Mau 2' in this study exhibited low virulence and pathogenicity between $20-30{ }^{\circ} \mathrm{C}$ but showed no infection at all at $10{ }^{\circ} \mathrm{C}, 40{ }^{\circ} \mathrm{C}$ and $50^{\circ} \mathrm{C}$. 

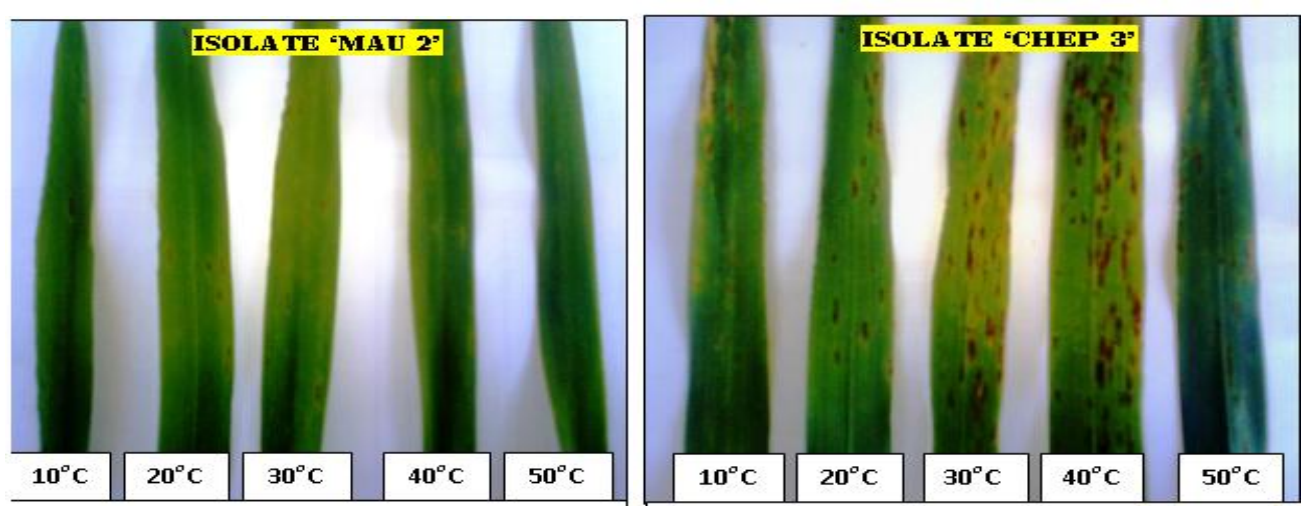

Plate1: Effect of temperature variation on pathogenicity of Pyrenophora teres isolates from low altitude 'CHEP 3' and high altitude 'MAU 2' zones. All isolates were exposed to each temperature for two minutes

This may mean that unlike 'Chep 3', this pathotype could be more sensitive to temperature variation. It is also possible that the gene-for-gene interaction between the host plant and the pathogen was not compatible thus restricting not only the infection process but also the disease development and symptom expression (Table 1, Plate 1).

For the individual isolates, Chep 3, Mau 6 and Mau 2 sourced from Chepkoilel and Mau Narok was the most virulent in descending order in terms of arithmetic means for the severity. However, each of the pathotypes responded differently to different temperatures at different time intervals. For example, the pathogenicity of Chep 3 increased from 30,40 and $50{ }^{\circ} \mathrm{C}$ at both 1 and 2 minutes intervals. On the other hand, Mau 2 showed low severity but at 2 minutes, the disease levels were higher than at 1 minute exposure to different temperature regimes. This means that Mau 2 can be more infectious when subjected to higher temperature over a long period of time. Similarly, Mau 6 pathotype was more virulent under different temperature regimes for a shorter period ( 1 minute) that at 2 minutes. This could mean that this pathotype is highly sensitive to temperature variation and becomes less infectious when exposed to higher temperatures over a long period of time (Table 2).

The two and three way interactions among the isolate, time interval and temperature variations were significant $(p<0.05)$. This may mean that both factors had additive effect on the observed virulence and pathogenicity (Table 2 ).

Table 2: Interaction effect of isolate, temperature regime and time duration on severity of P. teres in barley under greenhouse conditions

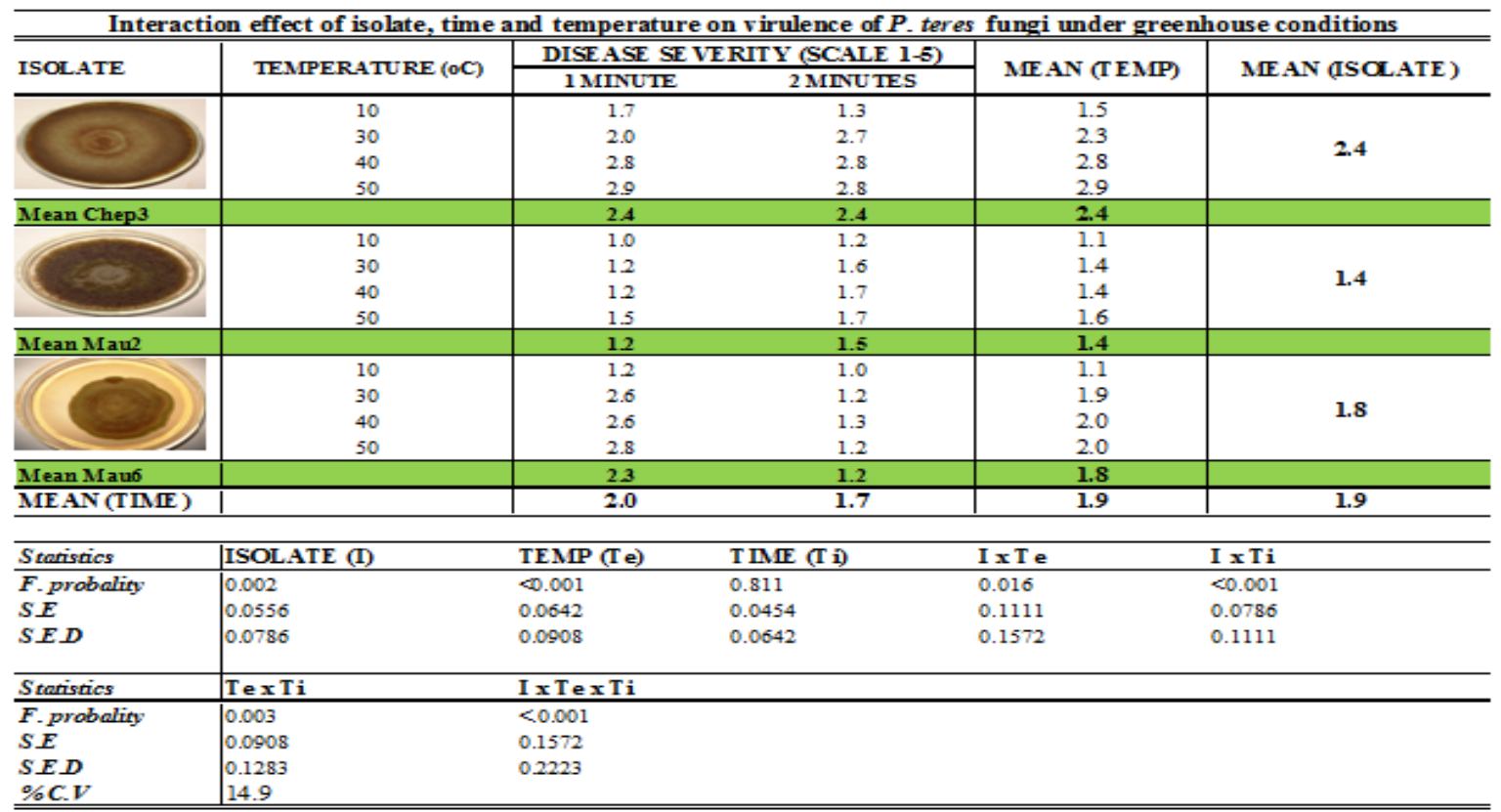

For instance, the severity levels of $P$. teres due to exposure of different isolates to different temperature regimes differed greatly (Table 2). This could be due to the additive effects of the 
pathotype factors such as genetic make-up and physical characteristics of the spores which enhanced the ability to remain infectious under different temperature regimes. Also, it is possible that there are some temperature and pathogen factors that interact to affect the level of the disease but this is not only inflenced by the pathogen and temperature only, but also duration taken by the pathogen under such conditions.

\section{CONCLUSIONS AND RECOMMENDATION}

Virulence and pathogenicity of $P$. teres $\mathrm{f}$. teres is significantly influenced by interaction effect of temperature and duration of exposure to each temperature regime. In addition, infection by this pathogen can occur at a wider temperature range of $10-50{ }^{\circ} \mathrm{C}$ when exposed for 2 minutes but this highly depends on the strain/pathotype. Maximum infection occurs at temperatures between $10-30$ ${ }^{\circ} \mathrm{C}$ which is a bit higher than what other researchers had observed. The study therefore recommends the need to determine the maximum time that this pathogen can withstand to remain infections especially at the $40-50{ }^{\circ} \mathrm{C}$ temperature ranges. This is very vital for virulence pathogenicity studies which aim at management of this disease

\section{REFERENCES}

Agrios G.N. (2005) Plant Pathology. 5th Edition ed. Amsterdam: Elsevier Academic Press, UK.

Bekele H., Shambel K., Abashamo L. (2001) Barley yield loss due to net blotch and leaf rust in Bale highlands. Pest Mgt. J. Eth. 5: 45-53.

Bentata F., Labhilili M., ElAissami A., Bary S., Yeslem C.H., Ibijbijen J. (2011) Analysis of diversity genetic of Moroccan net blotch populations using amplified fragment length polymorphism (AFLP) markers. African Journal of Biotechnology 10(39): 7548-7554.

EABL-UoE. (2010) Collaborative barley research programme: Breeding, Agronomy and Product Assessment Trials, KENYA.

EABL-UoE. (2013) Collaborative barley research programme: Breeding, Agronomy and Product Assessment Trials, KENYA.

Kosaida T. (2008) Influence of Temperature and Daylight Length on the Barley Infection by Pyrenophora teres. Plant Protection Research 48 (1): 9-15.

Kosiada T. (2008) Influence of Temperature and Daylight Length on Berley Infection by Pyrenophora teres. Journal of Plant Protection Research 48(1): 9-15.

Mathur S.B., K. Singh, J.K. Hansen. (1989) A working Manual on Some Seed-borne Fungal Diseases. Danish Government Institute of Seed Pathology for Developing Countries, Ryvangs Alle 78, DK-2900 Hellerup, Denmark.

McLean M.S., Howlett B.J., Hollaway G.J. (2009) The epidemiology and control of spot form of net blotch (Pyrenophora teres f. maculata) of barley: A review. Australasian Plant Pathology (In Press).

Owino A.A., Ochuodho J.O., Were J.O. (2013) Morphological diversity of net blotch fungi (Pyrenophora teres) infecting barley (Hordeum vulgare) in barley growing ares of Kenya Journal of Experimental Biology and Agricultural Science 1(6): 473-479.

Owino A.A., J. O. Ochuodho, J. O. Were, N. K. Rop. (2014) Response of Spring and Winter Barley to Pyrenophora teres Under High and Medium Altitude Zones of Kenya. International Journal of Research In Agriculture and Food Sciences 2(2): 1-10.

Than P.P., R. Jeewon, K.D. Hyde, S. Pongsupasamit, O. Mongkolporn, P.W.J. Taylor. (2008) Characterization and pathogenicity of Colletotrichum species associated with anthracnose on chilli (Capsicum spp.) in Thailand. Plant Pathology 57: 562-572.

Were J.O., Ochuodho J.O. (2012b) Virulence and pathogenicity of Colletotrichum sublineolum and Colletotrichum gloeosporioides from leaf, stem panicle tissues on advanced sorghum genotypes and genetic basis of observed responses. International Journal of Agricultural Sciences 2 (12): 336-345.

Xue A.G., Burnett P.A. (1995) Evaluation of interactions between Rhynchosporium secalis and Pyrenophora teres on barley. Phytoprotection 76 (1): 1-7. 


\section{AUTHORS' BIOGRAPHY}

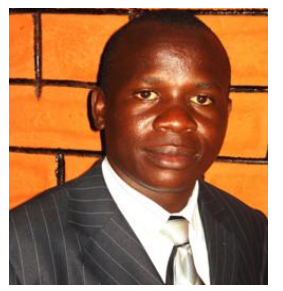

Javan Omondi Were Kenya, $\mathrm{PhD}$ Student (Pathology), Lecturer in Plant Pathology and Agriculture Biometry at University of Eldoret, School of Agriculture and Biotechnology, Department of Seed, Crop and Horticultural Science. Research Interests: Plant Pathology, Crop Physiology and Improvement in relation to Genetics.

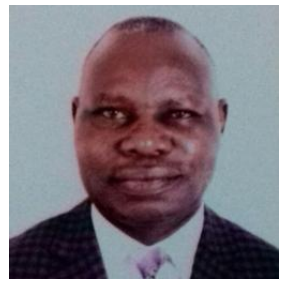

Julius Onyango Ochuodho Kenya, Professor at University of Eldoret, School of Agriculture and Biotechnology, Department of Seed, Crop \& Horticultural Sciences. Research interests - Seed Health, Plant Pathology, Plant Breeding and Genetics.

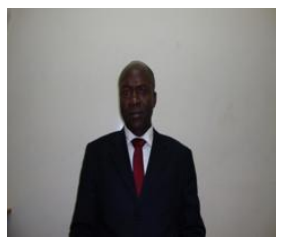

Nicholas Kipkemboi Rop Kenya, PhD (Pathology). Senior Lecturer (Plant Pathology) at University of Eldoret, School of Agriculture and Biotechnology, Department of Seed, Crop \& Horticultural Sciences. Research interests Molecular Plant Pathology.

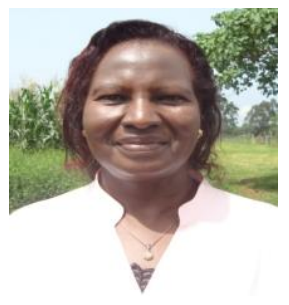

Elizabeth Nabwile Omami - Kenya, Professor at University of Eldoret, School of Agriculture and Biotechnology, Department of Seed, Crop \& Horticultural Sciences. Research interests - Plant Nutrition, Plant Physiology and Post-harvest Technology.

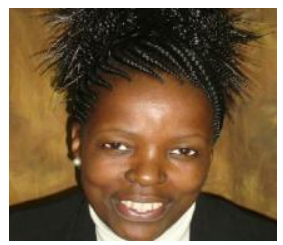

Victoria Esther Anjichi - Kenya, PhD (Seed Science). Lecturer University of Eldoret, School of Agriculture and Biotechnology, Department of Seed, Crop and Horticultural Sciences. Research Interests - Seed Science (seed health, physiology and quality aspects)

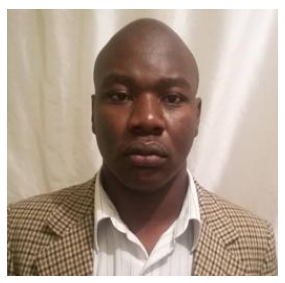

Presley Mostyn Ouma Odero - Kenya, MSc Student (Plant Protection Pathology). Research Assistant (EABL - UoE Barley Research Programme), University of Eldoret, School of Agriculture and Biotechnology, Department of Seed, Crop and Horticultural Sciences. Research Interests - Plant Pathology and Breeding.

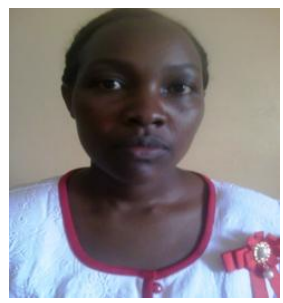

Lydia Kimno - Kenya, BSc (Agriculture). Crops Extension Officer in the Ministry of Agriculture, Livestock and Fisheries, Elgeyo Marakwet County. Research interest: Crop protection, Pathology.

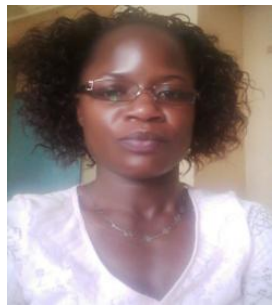

Abigael Adhiambo Owino - Kenya, MSc (Plant Pathology). Plant Pathologist at Kenya Agriculture \& Livestock Research Organization (KALRO), Tea Research Institute, Kericho County. Research interests - Plant Pathology. 